\title{
O PROCESSO DE REGIONALIZAÇÃO EM MINAS GERAIS: BREVE ABORDAGEM SOBRE REGIÃO METROPOLITANA DE BELO HORIZONTE, REGIÃO METROPOLITANA DO VALE DO AÇO E PROJETO DE LEI COMPLEMENTAR (PLC) 11/15 PARA INSTITUIÇÃO DA REGIÃO METROPOLITANA DE MONTES CLAROS
}

\author{
THE REGIONALIZATION PROCESS IN MINAS GERAIS: A BRIEF OVERVIEW OF BELO HORIZONTE AND VALE DO AÇO'S \\ METROPOLITAN AREAS AND THE BILL No11/15 FOR THE CREATION OF MONTES CLAROS' METROPOLITAN AREA
}

EL PROCESO DE REGIONALIZACIÓN EN MINAS GERAIS: BREVE PANORAMA DE LAS REGIONES METROPOLITANAS DE BELO HORIZONTE, DEL VALLE DEL ACERO Y DEL PROYECTO DE LEY (PLC 15/11) PARA LA INSTITUCIÓN DE LA REGIÓN METROPOLITANA DE MONTES CLAROS

\section{RESUMO}

Introdução: Minas Gerais é um estado que desempenha alto poder de polarização nacional, entretanto, apesar de sua extensão territorial, possui apenas duas regiões metropolitanas consolidadas, a saber Região Metropolitana de Belo Horizonte (RMBH), instituída pela Lei Complementar Federal $n^{\circ} 14$, de 1973, e a Região Metropolitana do Vale do Aço (RMVA), instituída pela Lei Complementar Estadual no 51/98 (alterada pelas Leis Complementares Estaduais no 90/2006 e no 122/2012). Essas regiões metropolitanas apresentam características distintas em relação à escala territorial e especificidades de uso e ocupação. Ademais, destacase também na rede urbana de Minas Gerais a cidade de Montes Claros, que exerce forte poder de influência regional no Norte de Minas, havendo interesse de instituição de uma região metropolitana por parte de seus gestores a partir do Projeto de Lei Complementar (PLC) no 11/15. Objetivo: Assim, define-se como objetivo geral deste artigo abordar brevemente acerca da Região Metropolitana de Belo Horizonte, da Região Metropolitana do Vale do Aço e sobre o Projeto de Lei Complementar (PLC) no 11/15 para instituição da Região Metropolitana de Montes Claros. Métodos: A pesquisa, de caráter qualitativo, utiliza como técnicas a análise documental, a partir da consulta a dados estatísticos do IBGE, e de documentos legais; e bibliográfica, por meio da análise da caracterização das regiões em estudo em artigos e publicações acadêmicas. Resultados: São relacionados no artigo os critérios legais para instituição das regiões metropolitanas, um breve histórico sobre a consolidação das regiões metropolitanas em Minas Gerais e investigação sobre as especificidades das Regiões Metropolitanas de Belo Horizonte, do Vale do Aço e do Projeto de Lei para instituição da Região Metropolitana de Montes Claros. Conclusão: Em considerações finais é destacado que, embora as regiões metropolitanas analisadas apresentem distinções em termos de porte populacional e escala territorial, ambas comungam problemas de gestão socioeconômica e demandam a adoção de políticas públicas integradas para desenvolvimento mais equilibrado.

Palavras-chave: Região metropolitana, Estatuto da Metrópole, RMBH, RMVA, Montes Claros.

\section{ABSTRACT}

Introduction: Minas Gerais is a state that has a high national polarization. However, despite its territorial extension, it has only two metropolitan areas: Metropolitan Area of Belo Horizonte (RMBH), established by Federal Law No. 14, 1973, and the Metropolitan Area of Vale do Aço (RMVA), instituted by the Minas Gerais Law No 51/98 (amended by the laws No 90/2006 and No 122/2012). These metropolitan areas have different characteristics concerning the territorial scale and specificities of use and occupation. Besides, the city of Montes Claros also stands out in the urban network of Minas Gerais, which has strong regional influence in the North of Minas Gerais, and interest from politicians to establish a metropolitan area there, based on Bill No 11/15. Objective: It is defined as the general objective of this article to briefly discuss the Metropolitan Areas of Belo Horizonte and Vale do Aço and Bill No 11/15 for the institution of the Metropolitan Area of Montes Claros.

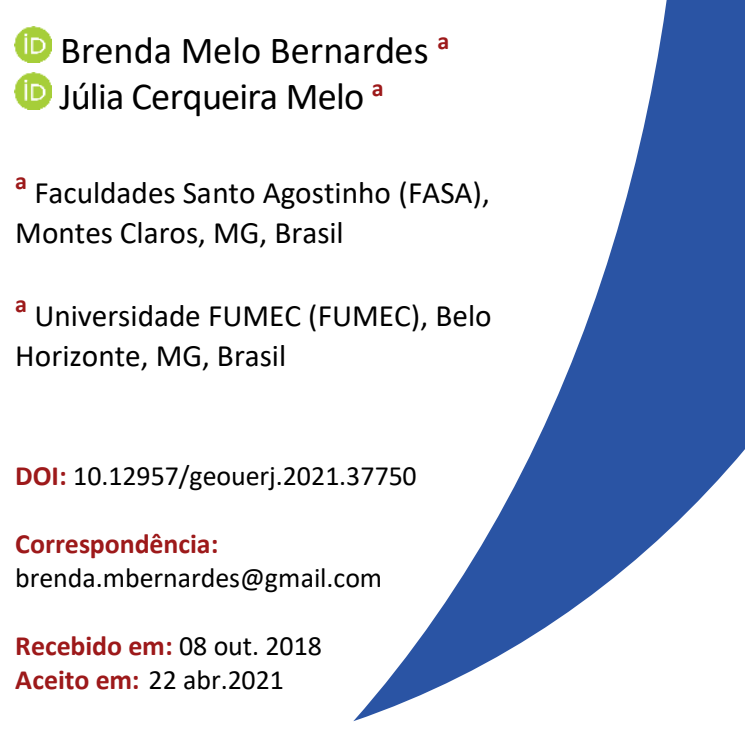


Methods: The qualitative research uses documentary analysis from IBGE statistical data, and legal documents, alongside bibliographic research, which examines the regions under study in academic articles and publications. Results: The article lists the legal criteria for the institution of metropolitan areas, a brief history of the institution of these in Minas Gerais and an investigation of the specificities of the metropolitan areas of Belo Horizonte, Vale do Aço and the Bill for the establishment of the Metropolitan Area of Montes Claros. Conclusion: In final considerations, it is highlighted that, although the metropolitan areas analyzed show distinctions in terms of population size and territorial scale, they share problems of socioeconomic management and demand the adoption of integrated public policies for equal development.

Keywords: Metropolitan area, Metropolis Statute, RMBH, RMVA, Montes Claros.

\section{RESUMEN}

Introducción: Minas Gerais es un Estado que desempeña un alto poder de polarización nacional. Sin embargo, pese a su extensión territorial, solo presenta dos regiones metropolitanas sólidamente establecidas, es decir, la Región Metropolitana de Belo Horizonte (RMBH), institucionalizada por la Ley Federal Complementaria No. 14, de 1973, y la Región Metropolitana del Valle del Acero (RMVA), institucionalizada por la Ley Complementaria del Estado no 51/98 (modificada por las Leyes Complementarias del Estado no 90/2006 y no 122/2012). Estas Regiones Metropolitanas tienen distintos atributos respecto a la escala territorial y las especificidades de uso y ocupación. Además, la ciudad de Montes Claros también se destaca en la red urbana de Minas Gerais, pues presenta fuerte influencia regional en el Norte de Minas Gerais, habiendo interés de que se instituya una Región Metropolitana, de parte de sus gestores, con base en el Proyecto de Ley Complementaria (PLC) no 15/11. Objetivo: Se define como objetivo general de este artículo tratar brevemente acerca de la Región Metropolitana de Belo Horizonte, de la Región Metropolitana del Valle del Acero y sobre el Proyecto de Ley Complementaria (PLC) no 11/15 para que se instituya la Región Metropolitana de Montes Claros. Métodos: La investigación de carácter cualitativo emplea como técnicas el análisis documental desde la consulta a datos estadísticos de IBGE y de documentos legales y bibliográficos, mediante el análisis de la caracterización de las regiones objeto de estudio en artículos y publicaciones académicas. Resultados: Los criterios legales para la institución de las regiones metropolitanas se enumeran en el artículo, una breve historia de la consolidación de las regiones metropolitanas en Minas Gerais y una investigación de las especificidades de las regiones metropolitanas de Belo Horizonte, del Valle del Acero y del Proyecto de Ley para la institución de la Región Metropolitana de Montes Claros. Conclusión: En consideraciones finales, se pone en relieve que, aunque las regiones metropolitanas consideradas presenten diferencias en términos de constitución poblacional y escala territorial, ambas comparten problemas de gestión socioeconómica y demandan la adopción de políticas públicas integradas para un desarrollo más equilibrado.

Palabras clave: Región Metropolitana, Estatuto de Metrópolis, RMBH, RMVA, Montes Claros. 


\section{INTRODUÇÃO}

O Estado de Minas Gerais, de acordo com o Censo do IBGE (2010), é considerado um dos mais populosos do Brasil. Apesar de apresentar alto poder de polarização nacional por concentrar indústrias, serviços e pela alta capacidade produtiva, tem suas especificidades no que tange a conformação da rede urbana. De acordo com o IBGE (2007), Minas Gerais apresenta distinções quanto aos tipos de conexões estabelecidas, ao sul destacam-se redes curtas, com uma ocupação mais compacta, em detrimento ao norte do Estado, em que predominam redes de longa distância, "Há casos que fogem ao padrão regional, como o de Montes Claros, no norte de Minas Gerais, que exerce um forte poder de atração no noroeste mineiro, com deslocamentos médios de $110 \mathrm{~km}$ como primeira opção (IBGE, 2008, p. 163)".

Não obstante, apesar da sua extensão territorial, Minas Gerais têm consolidadas apenas duas regiões metropolitanas: Região Metropolitana de Belo Horizonte (RMBH), instituída pela Lei Complementar Federal $n^{\circ}$ 14, de 1973, e a Região Metropolitana do Vale do Aço (RMVA), instituída pela Lei Complementar Estadual no 51/98 (alterada pelas Leis Complementares Estaduais no 90/2006 e no 122/2012). Desse modo, ainda que esses núcleos metropolitanos apresentam conformações distintas no que tange à escala territorial e características de ocupação, ambos precisam atender as exigências comuns legais estabelecidas pelo Estatuto da Metrópole quanto ao processo de caracterização e gestão.

Sendo assim, diante da problemática que assola as regiões metropolitanas brasileiras, marcadas por processos de segregação socioespacial, desigualdade econômica e distribuição desigual de investimentos públicos, considera-se que uma abordagem sobre as exigências jurídicas de instituição das regiões metropolitanas, associada ao estudo do processo de regionalização em Minas Gerais, poderá contribuir para elucidação dos desafios e entraves no seu processo de gestão. Coloca-se como objetivo principal, nesse sentido, abordar brevemente acerca da RMBH, da RMVA e sobre o Projeto de Lei Complementar (PLC) 11/15 para instituição da Região Metropolitana de Montes Claros, esse último, apesar de não ser classificado como região metropolitana, exerce forte influência regional no Norte de Minas.

Sobre o processo de estruturação do artigo, ele foi subdividido em análise dos critérios legais para instituição das regiões metropolitanas, que traz uma abordagem sobre as legislações relacionadas e parâmetros jurídicos; análise sobre a instituição das Regiões Metropolitanas em Minas Gerais, para compreensão do seu histórico de consolidação; e investigação sobre as especificidades das Regiões Metropolitanas de Belo Horizonte, do Vale do Aço e do Projeto de Lei para instituição da Região Metropolitana de Montes Claros. A pesquisa, de caráter qualitativo, traz ainda em considerações finais uma abordagem crítica sobre os desafios no processo de gestão, a partir da breve análise comparativa das regiões metropolitanas mineiras. 


\title{
CRITÉRIOS LEGAIS PARA A INSTITUIÇÃO DE REGIÕES METROPOLITANAS
}

Sobre os parâmetros legais que regem a instituição de regiões metropolitanas, conforme a Constituição Federal em seu artigo 25, §3으, os estados poderão instituir regiões metropolitanas, por meio de lei complementar (BRASIL, 1988). Em concordância, o Estatuto da Metrópole, Lei nô13.089 de 2015, dispõe:

\begin{abstract}
Art. 3o Os Estados, mediante lei complementar, poderão instituir regiões metropolitanas e aglomerações urbanas, constituídas por agrupamento de Municípios limítrofes, para integrar a organização, o planejamento e a execução de funções públicas de interesse comum. (BRASIL, Lei $\left.n^{\circ} 13.089,2015\right)$
\end{abstract}

Tratando-se do conceito de região metropolitana, para o mencionado Estatuto em seu artigo $2{ }^{\circ}$. VII, pode ser definida como: "unidade regional instituída pelos Estados, mediante lei complementar, constituída por agrupamento de Municípios limítrofes para integrar a organização, o planejamento e a execução de funções públicas de interesse comum" (BRASIL, 2015).

Ressalta-se que o Estatuto da Metrópole, nesse caso, exerce o papel legal de estimular o desenvolvimento metropolitano, visando fomentar ações integradas de planejamento urbano, quando estas extrapolam um município, entre os entes da federação, quais sejam, a União, os estados e os municípios (SANTOS, 2018).

Nesse contexto, é importante identificar os requisitos legais para a criação de uma região metropolitana, determinados pela Lei $n^{\circ} 13.089 / 2015$. Conforme seu artigo $3^{\circ}$, $\aleph^{\circ}{ }^{\circ}$, para a sua criação, estudos técnicos e audiências públicas devem ser realizadas em todos os municípios pertencentes à unidade territorial.

Ademais, estabelece o artigo 4ำ que na hipótese de uma região metropolitana que envolva municípios de diferentes estados da federação, é obrigatória a aprovação de lei complementar em cada um dos estados pertinentes. Complementa o parágrafo único, do referido artigo, que enquanto não aprovada a lei em todos os estados, a região metropolitana será validada somente naqueles em que a respectiva lei tiver sido aprovada.

A lei complementar, promulgada pelos estados, deverá estabelecer quais são os municípios integrantes da região metropolitana, bem como, quais são as funções públicas ou campos funcionais de comum interesse que fundamentam a implantação, ambos baseados em critérios técnicos. Existe também a obrigatoriedade de se precisar a estrutura de governança interfederativa e, igualmente, os canais de controle social (BRASIL, 2015).

Tais determinações são previstas no artigo 5ㅇ do Estatuto da Metrópole, que também estipula que o conceito de região metropolitana, mencionado anteriormente, deve ser respeitado. Exceção para as regiões metropolitanas criadas anteriormente à vigência da lei. 
Ainda, no que tange o presente trabalho e sua análise sobre as regiões metropolitanas mineiras tornase importante discutir sobre a legislação local. A Constituição do estado de Minas Gerais, em seu artigo 44, determina que a instituição da região metropolitana se baseará na avaliação de dados ou fatores, feitos por meio de parecer técnico e apurados de forma objetiva:

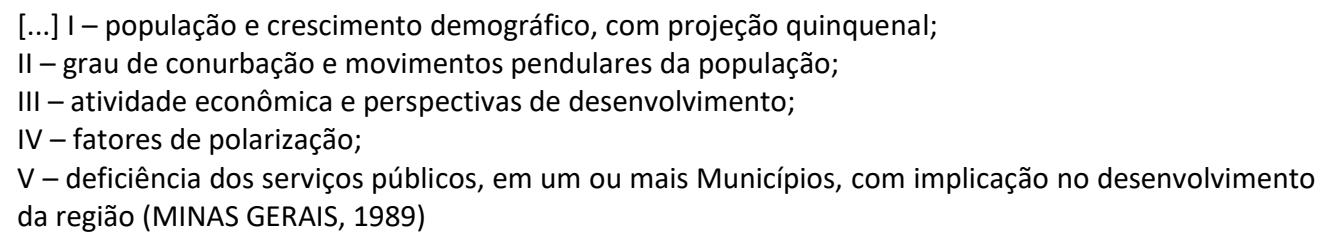

A Lei Complementar n88 de 2006 de Minas Gerais determina que o parecer técnico deve se basear em informações de fontes especializadas e ser produzido por instituição de pesquisa com reconhecida experiência e saber acerca de estudos urbanos e regionais. Ademais, os municípios interessados receberão as informações coletadas e análise da instituição de pesquisa para manifestação. Relevante destacar que, conforme legislação mineira, a região metropolitana não poderá ser instituída com população menor que seiscentos mil habitantes (MINAS GERAIS, 2006).

A expansão da cidade afora de seus limites é a razão da região metropolitana. Nesta estrutura haverá influência social e econômica de um núcleo urbano principal sob as demais cidades (MENCIO, 2015). Em concordância, depreende-se da lei complementar mineira que a instituição da região metropolitana se baseará também no "grau de conurbação e movimentos pendulares da população" (MINAS GERAIS, 2006).

No que tange a administração e organização das regiões, o Estatuto da Metrópole usa-se do conceito de governança interfederativa, determinando a prevalência dos princípios do interesse comum em detrimento do local, responsabilidade compartilhada, no que tange o desenvolvimento urbano integrado, autonomia entre os entes, observância do que é peculiar regional e de características de âmbito local, gestão democrática, uso dos recursos públicos de forma efetiva e desenvolvimento sustentável.

A referida lei determina também diretrizes a serem seguidas, nos artigos 7으, 7ㅇ-A e 8ㅇ․ Este último artigo determina as estruturas básicas necessárias para a governança interfederativa, quais sejam: uma instância executiva integrada pelos representantes do executivo dos entes; uma instância colegiada e deliberativa que tenha a sociedade civil representada; organização pública que tenha funções técnico-consultivas; e sistema integrado de prestação de contas, bem como de alocação de recursos (BRASIL, 2015).

Importante destacar que o Estatuto da Metrópole determina a obrigatoriedade do plano de desenvolvimento urbano integrado para as regiões metropolitanas, devendo ser elaborado de forma conjunta entre a sociedade civil, o estado e os municípios integrantes. A instância colegiada deliberativa, parte da governança interfederativa, aprovará o plano e encaminhará para análise da Assembleia Legislativa. A Lei 
estadual que aprovar o referido plano deverá ser revista, no mínimo, a cada 10 (dez) anos. Ressalta-se que a obrigatoriedade deste plano não exime os municípios da formulação do respectivo plano diretor, na verdade, o ente deverá compatibilizar seus dois planos (BRASIL, 2015).

Acerca do plano de desenvolvimento urbano integrado, o Estatuto determina uma estrutura mínima que contenha, dentre outros princípios: “diretrizes para as funções públicas de interesse comum, incluindo projetos estratégicos e ações prioritárias para investimentos"; "diretrizes quanto à articulação intersetorial das políticas públicas afetas à unidade territorial urbana"; e "o sistema de acompanhamento e controle de suas disposições". Ademais, durante a elaboração e fiscalização de sua aplicação assegura-se a promoção de audiências públicas e debates, a publicação dos documentos e informações que foram produzidos e a participação do Ministério Público (BRASIL, 2015).

No mesmo sentido, a Constituição mineira determina que a região metropolitana deverá possuir, entre outras coisas, um Plano Diretor de Desenvolvimento Integrado, bem como, um Fundo de Desenvolvimento Metropolitano (MINAS GERAIS, 1989). A lei complementar mineira n88 também legisla sobre o tema, destacando-se o artigo 6으, §2으, que determina a necessidade de se articular na elaboração do Plano participativo representantes de interesses sociais, econômicos e culturais, assim como o envolvimento de instituições relevantes para a escala de atuação regional (MINAS GERAIS, 2006).

A supracitada legislação estabelece que o fundo de desenvolvimento metropolitano - FDM objetiva o "financiamento da implantação de programas e projetos estruturantes e a realização de investimentos relacionados à funções públicas de interesse comum nas Regiões Metropolitanas do Estado" (MINAS GERAIS, 2006).

Acerca do tema, a lei estabelece que cada região metropolitana terá uma subconta no fundo, e que os beneficiários poderão ser:

Art. 20. Poderão ser beneficiárias do Fundo de Desenvolvimento Metropolitano instituições públicas, organizações não governamentais, organizações sociais de interesse público, empresas prestadoras de serviços públicos de interesse comum e outras entidades executoras ou responsáveis por estudos, projetos ou investimentos direcionados às Regiões Metropolitanas (MINA GERAIS, Lei Complementar $\left.\mathrm{n}^{\circ} 88,2006\right)$.

Bem como, determina quais são os recursos do fundo de desenvolvimento metropolitano, como por exemplo, mas não exaustivamente: recursos destinados pelo estado e municípios; dotações orçamentárias, entre elas transferências realizadas pela União; e auxílios e subvenções (MINAS GERAIS, 2006).

Isto posto, diante dos critérios legais que instituem e caracterizam as regiões metropolitanas, considerase necessário o entendimento do processo de regionalização em Minas Gerais e a aplicabilidade desses princípios no contexto mineiro. 


\section{BREVE ANÁLISE SOBRE A INSTITUIÇÃO DAS REGIÕES METROPOLITANAS EM MINAS GERAIS}

O processo de regionalização, muitas vezes, surge como alternativa para facilitar a obtenção de recursos financeiros pelos municípios de entes federais e estatais e para viabilizar a execução de funções públicas que sejam de interesse coletivo. Desse modo, diante dos problemas sociais, ambientais e econômicos que assolam as cidades de um modo geral, torna-se cada vez mais emergente a necessidade de estabelecimento de políticas públicas integradas e da cooperação interinstitucional, uma vez que, os municípios, isoladamente, lidam com dificuldades no processo de gestão pelos escassos recursos orçamentários e pelo excesso de responsabilidades atribuídas (MARRA, 2012).

As redes urbanas, de acordo com Côrrea (2001, p.424) são entendidas como "conjunto de centros funcionalmente articulados", ou seja, são constituídas pela interação de cidades em diferentes escalas de influência, que estabelecem redes de conexão em função dos fluxos instituídos de pessoas, mercadorias e comunicação.

Côrrea (2001) coloca que, até meados da década de 1960, as redes urbanas eram caracterizadas, além da rígida hierarquia, pelo menor grau de articulação entre as centralidades e pela baixa complexidade funcional. Atualmente, presencia-se uma hierarquia mais flexível de cidades em que a dinamização dos fluxos que comportam não extingue a estrutura hierarquizada, mas estimula novas interações entre cidades que independem do porte, das funções urbanas ou da sua localização (OLIVEIRA, 2008). Presencia-se, desse modo, a:

“[...] redefinição da rede urbana brasileira por meio das estruturas já existentes, ou seja, a polarização das grandes metrópoles em escala nacional, mas também a inserção dos espaços não metropolitanos, isto é, as cidades médias e pequenas, como "nós" de articulação da rede" (FRANÇA, SOARES, 2012, p. 172).

Nesse sentido, as cidades locais podem sobressair como centros regionais, resultando no processo de descentralização por meio da constituição de subníveis na rede urbana.

De acordo com estudos do IBGE (2008, p. 9), no contexto nacional, as interações estabelecidas pela rede urbana são provenientes de fluxos "[...] de produção e distribuição, de prestação de serviços, de gestão política e econômica - cujos nós são constituídos pelas cidades". Desse modo, destacam-se como níveis hierárquicos dos centros urbanos brasileiros as configurações de (1) Metrópole, (2) Capital Regional, (3) Centro Subregional, (4) Centro de Zona e (5) Centro Local.

Ainda como parte do processo de hierarquização da rede urbana, Balbim, Becker e Costa (2011) enfatizam que, com o processo de regionalização e, consequentemente, de formação de regiões 
metropolitanas, passa a ser instituída a cidade-núcleo, que desempenha o importante papel de ordenamento das funções públicas de interesse comum do seu núcleo metropolitano e de sua área de influência, constituída por municípios conurbados ${ }^{1}$. Apesar de atualmente existirem 74 regiões metropolitanas no país² (IBGE, 2020), verifica-se como problemática a desvinculação entre as exigências legais de instituição dessas regiões e de seu reconhecimento e caracterização, visto que existe um número expressivo de aglomerações no Brasil que possuem o estatuto de Região Metropolitana sem, contudo, resultar no processo de conurbação entre a cidade-núcleo e áreas de influência (BALBIM; BECKER; COSTA, 2011).

As primeiras regiões metropolitanas no Brasil foram instituídas por leis complementares federais, de acordo com os preceitos estabelecidos pela Constituição de 1967. Com a promulgação da Constituição de 1988, que concedeu maior autonomia aos municípios para o planejamento urbano no âmbito local, houve a transferência de responsabilidade de criação e gestão das regiões metropolitanas do governo federal para os estados (OBSERVATÓRIO DAS METRÓPOLES, 2010). Ademais, durante o período militar, na década de 1970, a consolidação das Regiões Metropolitanas passou a constituir também estratégia de estímulo ao desenvolvimento nacional, promovendo ações do governo federal para a instituição de políticas públicas integradas, almejando o crescimento econômico e investimentos em infraestrutura social e urbana (BALBIM; BECKER; COSTA, 2011).

Em Minas Gerais, o processo de gestão das regiões metropolitanas ocorre em consonante com as diretrizes estabelecidas pela Lei Complementar 88/2006. São determinados, dentre outros princípios, a colaboração entre o Estado e os municípios que integram a região metropolitana, a construção de políticas públicas que efetivem a redução de desigualdade social e territorial e que estimulem o cumprimento das funções públicas de interesse comum (PEREIRA, 2007).

Instituídas a partir das Leis Complementares federal no 14 de 1973, e Leis Complementares estadual no 89 e no $90^{3}$, de 2006, atualmente o Estado de Minas Gerais dispõem de apenas duas regiões metropolitanas (Figura 1), a saber: a Região Metropolitana de Belo Horizonte - RMBH e a Região Metropolitana do Vale do Aço - RMVA (PEREIRA, 2007). Não obstante, o Projeto de Lei Complementar 11/2015 propõe a instituição da Região Metropolitana de Montes Claros, diante da influência que esta capital regional exerce no noroeste mineiro (IBGE, 2008).

\footnotetext{
1 Souza (2011) define o conceito de aglomeração sem conurbação como os vínculos estabelecidos entre municípios, sobretudo por motivo econômico, em relação aos bens produzidos e serviços ofertados. Já a aglomeração com conurbação é caracterizada pela conformação de uma mancha urbana entre os municípios que dificulta a identificação de seus limites político-administrativos, uma vez que esses estabelecem forte relação de troca e dependência por motivos diversos (econômicos, culturais, administrativos).

2 Informação obtida a partir da última atualização do IBGE, em junho de 2020, que atualiza Regiões Metropolitanas (RMs), Regiões Integradas de Desenvolvimento (RIDEs) e Aglomerações Urbanas que são instituídas pelos governos estaduais e pela União (IBGE, 2020).

3 A Lei Complementar mineira no 90/2006 que atualmente dispõe sobre a Região Metropolitana do Vale do Aço em seu artigo 10 revogou a Lei Complementar no 51/1998 que originalmente instituía a mencionada região metropolitana.
} 
Figura 1. Regiões metropolitanas de Minas Gerais e o município de Montes Claros. Fonte: Fórum Nacional de Entidades Metropolitanas, 2018. Adaptado pelo autor.

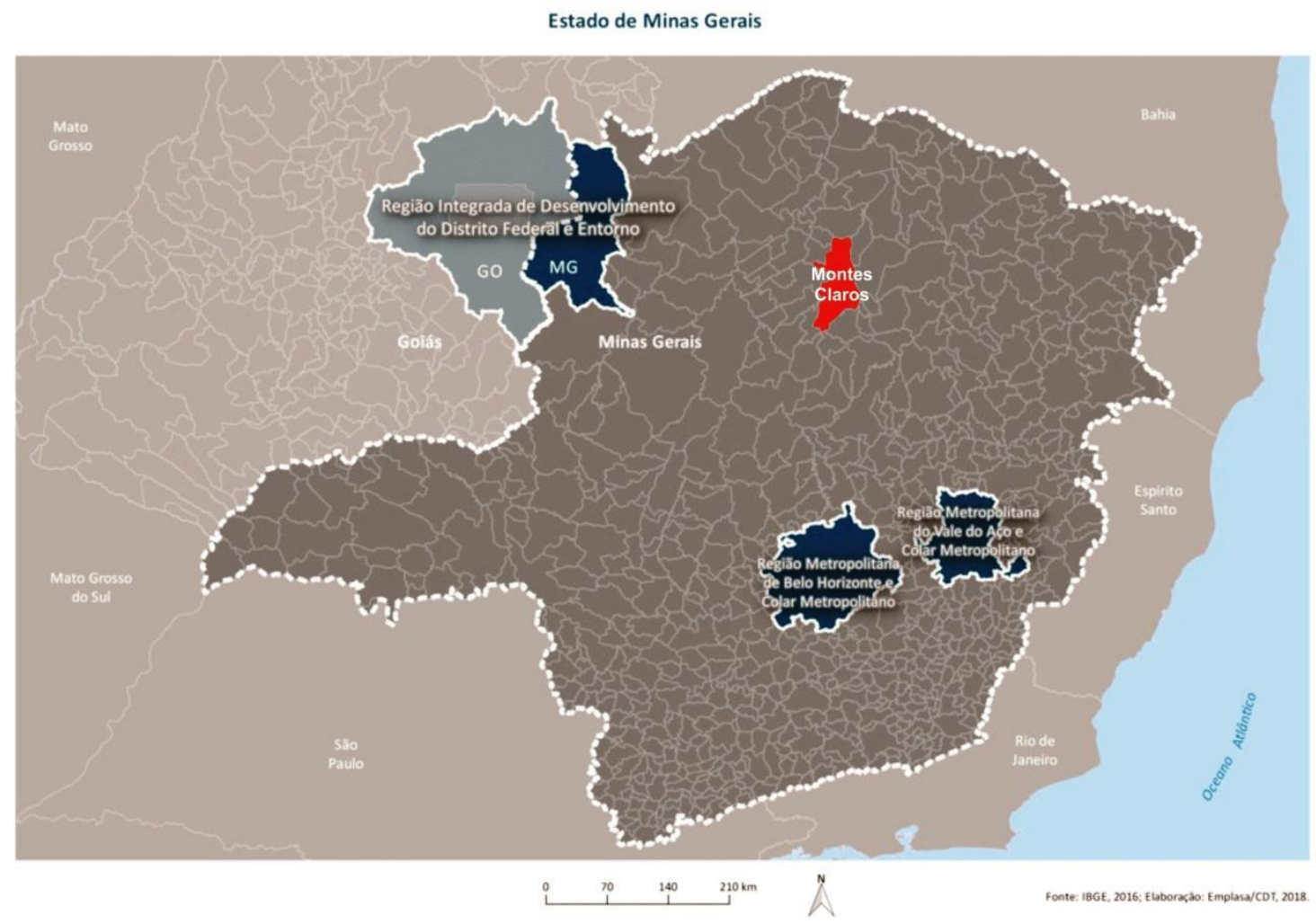

\section{Região Metropolitana de Belo Horizonte}

A Lei Complementar Federal $n^{\circ}$ 14, de 1973, sancionou as regiões metropolitanas de São Paulo, Belo Horizonte (Figura 2), Porto Alegre, Recife, Salvador, Curitiba, Belém e Fortaleza. De acordo com a referida lei, inicialmente a RMBH era constituída por 14 municípios, a saber: "Belo Horizonte, Betim, Caeté, Contagem, Ibirité, Lagoa Santa, Nova Lima, Pedro Leopoldo, Raposos, Ribeirão das Neves, Rio Acima, Sabará, Santa Luzia e Vespasiano" (BRASIL, 1973). Atualmente, a Região Metropolitana de Belo Horizonte é classificada, de acordo com os critérios de hierarquia urbana do IBGE (2008), como Metrópole Nível 1C, devido ao seu porte e capacidade maior de influência do que os demais centros urbanos, estando abaixo apenas de São Paulo, Grande Metrópole Nacional (1A) e do Rio de Janeiro, Metrópole Nacional (1B). A RMBH é composta por 34 municípios $^{4}$, além dos 16 municípios que fazem parte do seu colar metropolitano (AGÊNCIA DE DESENVOLVIMENTO DA RMBH, 2020).

Ao analisar a população residente na Região Metropolitana a partir de dados do IBGE de 2018, constatase uma população residente de, aproximadamente, 6 milhões de habitantes (SEGUNDO et al, 2020). Essa

${ }^{4}$ Dados obtidos a partir do Plano Diretor de Desenvolvimento Integrado da Região Metropolitana de Belo Horizonte (MINAS GERAIS, 2011). 
característica reforça a alta concentração populacional em arranjos territoriais de escala regional (FÓRUM NACIONAL DE ENTIDADES METROPOLITANAS, 2018a).

Figura 2. Região Metropolitana de Belo Horizonte. Fonte: Fórum Nacional de Entidades Metropolitanas, 2018

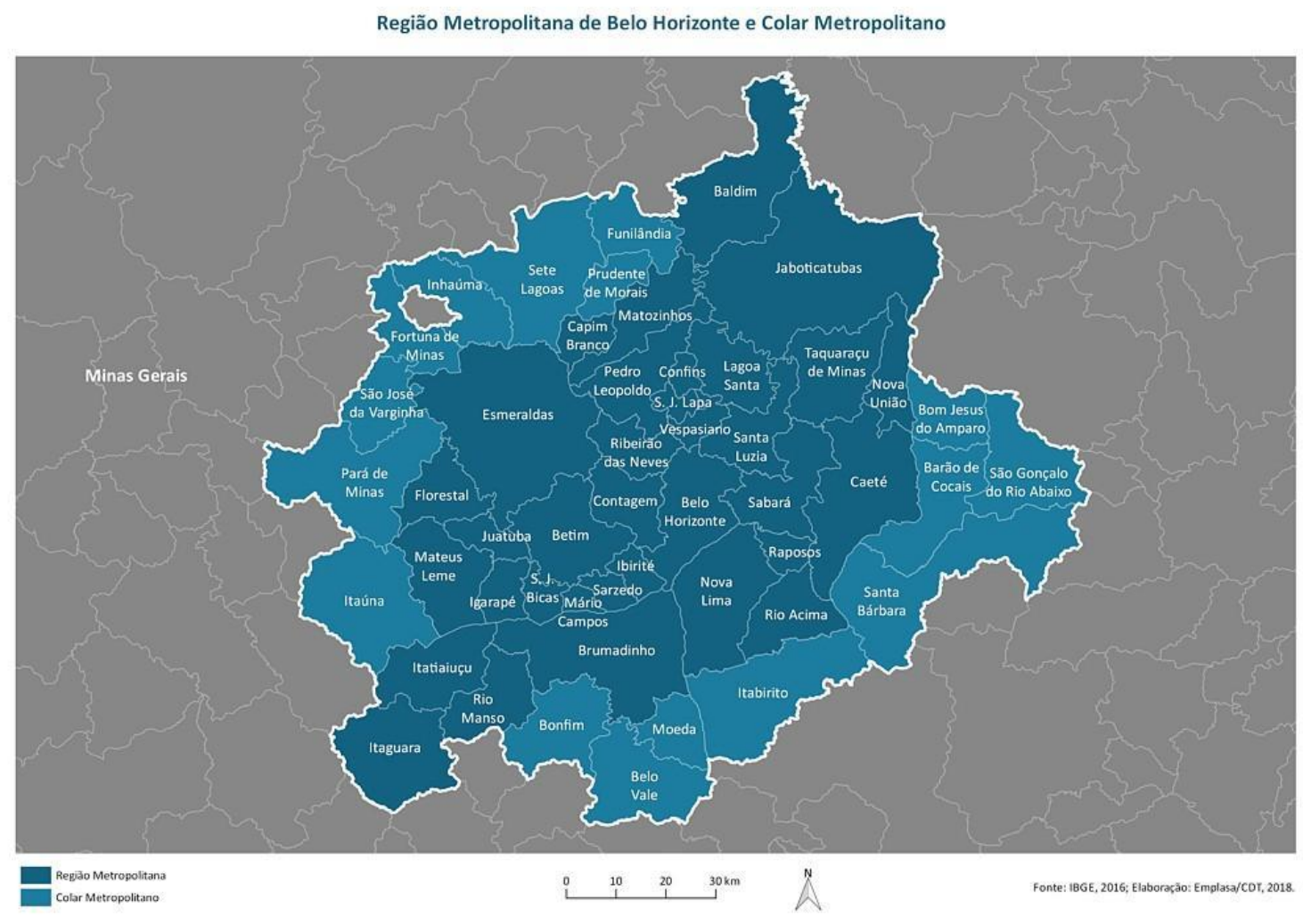

Ainda de acordo com a Lei Complementar federal, caberia às regiões metropolitanas instituídas em 1973 a formação de um conselho consultivo no intuito de orientar o conselho deliberativo sobre a adoção de diretrizes voltadas ao atendimento dos interesses comuns entre os municípios e auxiliar no desenvolvimento dos planos regionais. Já o conselho deliberativo teria a incumbência de desenvolver o Plano de Desenvolvimento Integrado e de coordenar a execução dos programas e serviços de interesse comum (BRASIL, 1973). É importante enfatizar que desde esse período já era instituído legalmente a importância da elaboração de planos de desenvolvimento integrado, de forma a estimular a prosperidade dos municípios considerando suas especificidades e carências em âmbito metropolitano, sob os aspectos econômico, social e de mobilidade.

Sobre o processo histórico de consolidação da RMBH, a instituição de Belo Horizonte como núcleo metropolitano foi impulsionada, principalmente, pelos investimentos estatais realizados na capital durante as décadas de 1940 e 1950, o que deu início ao processo de conurbação com os municípios vizinhos, sobretudo situados à Oeste e Norte. Destaca-se, nesse sentido, a implantação da Cidade Industrial Coronel Juventino 
Dias, em Contagem, e o prolongamento da Avenida Amazonas. Tais intervenções consolidaram o Vetor Oeste, de caráter industrial, como um dos principais eixos de expansão metropolitano (SOUZA, 2008).

Outro eixo que consolidou o processo de expansão periférica da RMBH nesse período inicial é o Vetor Norte, em função de investimentos públicos realizados como a implantação do Complexo de Lazer da Pampulha, instalação dos distritos industriais de Santa Luzia e Vespasiano e abertura da Avenida Antônio Carlos (SOUZA, 2008). Assim, o processo de industrialização e o aumento populacional, intensificados a partir da década de 1970, foram fatores determinantes no processo de regionalização e de definição dos principais eixos de expansão do núcleo metropolitano. Mendonça, Andrade e Diniz $(2015$, p.16) confirmam essa questão ao colocar que:

\begin{abstract}
Na segunda metade da década de 1970, a chamada nova industrialização mineira, que promoveu diversificação industrial e manteve altas taxas de crescimento econômico, ainda alguns anos após o declínio do milagre brasileiro, foi também resultado de um forte aparato técnico-institucional estatal e de suas ações: legislação de incentivos fiscais, investimento em infraestrutura e cessão de terrenos a indústrias e investimentos diretos em atividades industriais e terciárias.
\end{abstract}

Atualmente a RMBH é estruturada a partir de seis vetores de expansão, como os de ocupação mais antiga destacam-se o Vetor Norte, que abriga o Aeroporto Internacional Tancredo Neves, a Cidade Administrativa de Minas Gerais e onde verifica-se tendência de ocupação por condomínios fechados e loteamentos irregulares; e o Vetor Oeste, que conforma o eixo-industrial Contagem - Betim, responsável também pelo abastecimento de $\mathrm{BH}$ pelas atividades predominantes agropecuárias. Ainda constituem áreas de expansão territorial os vetores Sul, Leste, Sudoeste e Noroeste (UFMG, 2014). Nesse sentido, Belo Horizonte configura-se como uma região com alto poder de polarização em escala regional, destacando-se pelas conexões estabelecidas de gestão empresarial, na oferta de serviços de saúde, de ensino superior e de lazer (IBGE, 2008).

No que tange o planejamento e gestão da $\mathrm{RMBH}$, o processo foi caracterizado por dois momentos significativos: o primeiro correspondeu à instituição da Superintendência de Desenvolvimento da Região Metropolitana de Belo Horizonte, mais conhecida como PLAMBEL, e o segundo período, de procedência recente, trata-se da elaboração do Plano Diretor de Desenvolvimento Integrado -PDDI da RMBH (TONUCCI FILHO, 2012).

Em seus estudos conduzidos sobre a trajetória do processo de regionalização, Tonucci Filho (2012) coloca que a PLAMBEL, autarquia estadual, foi instituída como órgão gestor da RMBH em 1974. Constituído por um corpo técnico da Fundação João Pinheiro, esse órgão foi responsável por uma produção significativa de diagnósticos sobre a região metropolitana, com atuação mais destacada nas áreas de planejamento de transportes e uso e ocupação do solo. Tais estudos resultaram na publicação pelo Conselho Deliberativo em 1975 de documentos relevantes para a gestão metropolitana: o Plano de Ocupação do Solo da Aglomeração 
Metropolitana (POS), o Plano Metropolitano de Transportes e o Plano de Desenvolvimento Integrado Econômico e Social da RMBH - PDIES (TONUCCI FILHO, 2012).

Já o PDDI-RMBH foi desenvolvido por uma equipe multidisciplinar coordenada pelo "Centro de Desenvolvimento e Planejamento Regional - Cedeplar, da Faculdade de Ciências Econômicas - FACE, da Universidade Federal de Minas Gerais - UFMG" que contou com a participação de "professores e pesquisadores de outras unidades de ensino superior e centros de pesquisa no Estado, além de consultores nas áreas de planejamento urbano e ambiental, transportes, políticas públicas e outros estudos setoriais" (MINAS GERAIS, 2011, p.1). O Plano, que foi concluído em 2010, apresenta perspectivas de desenvolvimento para 2023 e tem como um dos objetivos principais estimular o desenvolvimento local dos municípios que carecem de investimentos e de melhorias em infraestrutura urbana. Tal estratégia pressupõe o envolvimento dos municípios que integram a RMBH na elaboração do PDDI, no desenvolvimento do diagnóstico e na formulação de diretrizes, além da contribuição municipal na constituição do Fundo Metropolitano (MINAS GERAIS, 2011).

É importante enfatizar sobre a consolidação do processo de metropolização de Belo Horizonte que o modelo de planejamento radio-concêntrico resultou, inicialmente, na definição de uma estrutura mononuclear, que estabeleceu forte relação de dependência entre o núcleo metropolitano e municípios adjacentes, situados em áreas mais periféricas. Atualmente, como estratégia de reestruturação territorial definida pelo Plano Diretor de Desenvolvimento Integrado (PDDI), verifica-se o interesse de descentralização de investimentos em infraestrutura urbana e de atividades que impulsionam essa dependência dos municípios periféricos em relação ao núcleo metropolitano, relacionado com oferta de serviços, empregos e comércio (MINAS GERAIS, 2011). Ressalta-se ainda a partir do PDDI que:

A redução das desigualdades socioespaciais passa necessariamente pela transformação da RMBH numa metrópole policêntrica e mais compacta, em oposição a um crescimento extensivo ou contínuo da mancha urbana do tipo centro-periferia, prevalecente até hoje (MINAS GERAIS, 2011, p. 11).

No Brasil, bem como nos demais países da América Latina, verifica-se uma tendência de reestruturação de um espaço metropolitano expandido e fragmentado, que tem resultado em novos arranjos estabelecidos entre os poderes econômico, político e/ou territorial. Essas transformações urbanas transcendem, muitas vezes, os limites da articulação metropolitana, alimentado pela possibilidade da incorporação de redes de conectividade informacional nos processos cada vez mais dinâmicos (MOURA, 2012).

Esse fenômeno resulta na transformação da estrutura mononuclear metropolitana em uma estrutura polinuclear, interconectada e múltipla quanto às características de ocupação, de modos de vida, de interesses individuais de consumo, de diversidade de apropriações e de territórios. Essa interconectividade entre territórios, que transcende os limites metropolitanos e a estrutura tradicional, pode ser classificado, segundo 
Moura (2012), como arranjo urbano-regional. Ressalta-se aqui, entretanto, que essa constituição fragmentada da metrópole não pode ser descrita como um processo recente, mas como uma continuidade do processo de urbanização das metrópoles intensificado pelos efeitos da globalização (LACERDA, 2012).

Em Belo Horizonte, esse rearranjo territorial visa constituir uma estrutura policêntrica intensificada pelas conectividades estabelecidas por uma rede de mobilidade multi-modal. Ressalta-se que essa estratégia não pretende ampliar os limites territoriais da mancha urbana conurbada, mas promover o adensamento de áreas subutilizadas, a intensificação da diversidade de usos internos, a requalificação dos eixos viários e a recuperação de áreas de interesse ambiental (MINAS GERAIS, 2011).

Por fim, é importante mencionar nessa breve abordagem a importância desempenhada pela Agência Metropolitana da RMBH, instituída pela Lei Complementar mineira 107, de 12 de janeiro de 2009, no desenvolvimento de estudos relacionados com o macrozoneamento de uso e ocupação do solo e plano de mobilidade metropolitano, na concessão de suporte técnico aos municípios integrantes da RMBH para gestão das questões de influência regional e no processo de elaboração de planos diretores municipais em conformidade com as diretrizes expressas no PDDI, possibilitando maior interação das políticas públicas em categoria interfederativa (AGÊNCIA DE DESENVOLVIMENTO DA RMBH, 2019).

\section{Região Metropolitana do Vale do Aço}

De formação mais recente, quando comparado à RMBH, a RMVA (Figura 3) foi instituída a partir de 1998 e é composta por quatro municípios - Coronel Fabriciano, Ipatinga, Santana do Paraíso e Timóteo, e outras 24 cidades que fazem parte do colar metropolitano. Sobre volume populacional, a RMVA que, a partir de estimativa do IBGE 2017, apresentava 493 mil habitantes (CALDEIRA JUNIOR, 2018), registrou decréscimo populacional, considerando os dados do IBGE no ano de 2017, totalizando 276.457 habitantes (FÓRUM NACIONAL DE ENTIDADES METROPOLITANAS, 2018b). Essa característica mostra que atualmente a região metropolitana não atenderia aos critérios definidos pela Lei Complementar n88 de 2006 de Minas Gerais, que estipula porte populacional de, no mínimo, 600 mil habitantes (MINAS GERAIS, 2006).

Entretanto, ressalta-se que os critérios da lei não se aplicam nesse contexto, uma vez que foi promulgada depois da criação da RMVA. Assim, vale destacar que a Região Metropolitana em questão é formada por cidades de médio porte, sem a preponderância de polaridade regional de um núcleo da rede urbana sobre os demais, apesar de Ipatinga ser vista como referência na oferta de trabalho e serviços (CALDEIRA JUNIOR, 2018). 
Figura 3. Região Metropolitana do Vale do Aço. Fonte: Fórum Nacional de Entidades Metropolitanas, 2018.

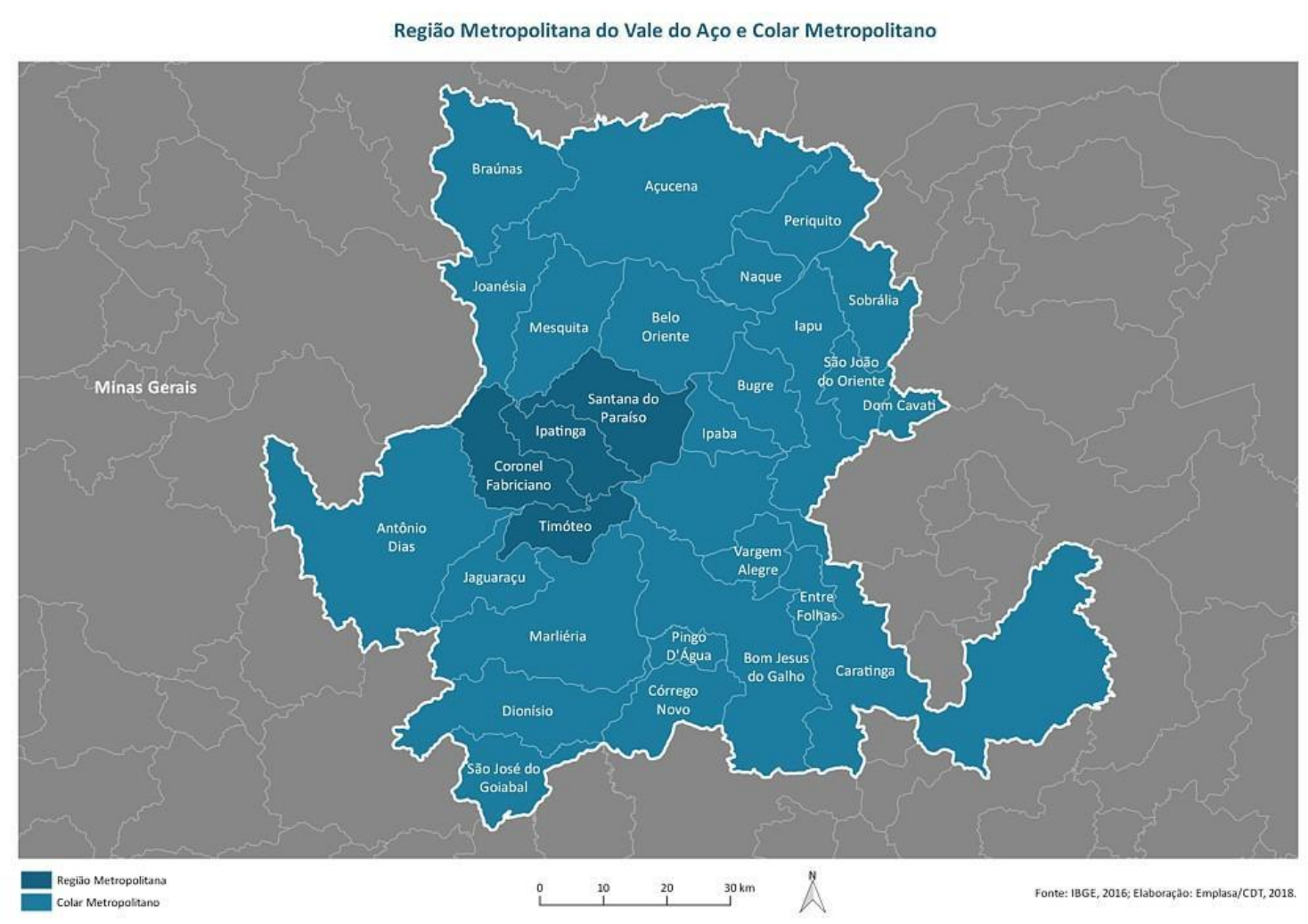

Conhecida inicialmente como Vale Verde, em função da extensa cobertura vegetal de Mata Atlântica que caracteriza o território margeado pelo Vale do Rio Doce, a porção Leste de Minas Gerais é de ocupação recente, visto que manteve uma posição de isolamento em relação às demais localidades mineiras durante o período de exploração colonial pela Coroa Portuguesa e Republicano. Assim, a região teve seu processo de desenvolvimento econômico impulsionado, sobretudo, pela implantação da Estrada de Ferro Vitória - Minas (EFVM), no século XX (BARBOSA, 2010).

Essa conexão ferroviária, aliada à riqueza mineral da região, caracterizada pela expressiva concentração de jazidas de minério de ferro, atraíram, entre as décadas de 1930 e 1950, empresas siderúrgicas de grande porte como a antiga Companhia Belgo-Mineira (hoje ArcelorMittal João Monlevade), a ACESITA (atualmente ArcelorMittal Timóteo) e a USIMINAS em Ipatinga. Posteriormente, foi implantada em Belo Oriente a fábrica de celulose - Cenibra, que também contribuiu para o processo de urbanização. Não obstante, a implantação dessas empresas impulsionaram o surgimento dos núcleos urbanos de Coronel Fabriciano e, em sequência, a emancipação de seus distritos Ipatinga e Timóteo, que futuramente deram origem à região metropolitana.

Costa e Santos (2002) enfatizam que, considerando a expansão econômica e populacional na região do Vale do Aço, com o desenvolvimento impulsionado pela instalação das siderúrgicas e, consequentemente, a consolidação do processo de conurbação entre os municípios adjacentes, deveriam ser incorporados também à Região Metropolitana instituída os municípios de Mesquita, que configura área de ocupação periférica contígua à Ipatinga e sede de um distrito 
industrial; e o município de Belo Oriente, sede da Cenibra. Vale destacar que esse processo de urbanização e industrialização induziu o desmatamento das extensas reservas de mata atlântica que caracterizavam a região, que antes conhecida como Vale Verde, hoje é denominada de Vale do Aço (BARBOSA, 2010).

No que tange os critérios legais de gestão da região metropolitana, a elaboração na década de 1970 do Plano de Desenvolvimento Integrado do Vale do Aço pela Fundação João Pinheiro já manifestava o interesse público em diversificar as atividades econômicas da região a partir da elaboração de um diagnóstico direcionado para o estudo da economia regional e urbana (COSTA; SANTOS, 2002). Não obstante, considerando as exigências estabelecidas pelo Estatuto das Metrópoles de consolidação de um Plano Metropolitano para as regiões metropolitanas e aglomerações urbanas institucionalizadas no país, o Conselho Deliberativo de Desenvolvimento Metropolitano (CDDM) da RMVA aprovou em 2019 o Projeto de Lei do Plano Diretor de Desenvolvimento Integral (PDDI) da região (SECRETARIA DE DESENVOLVIMENTO ECONÔMICO, 2019), que tem a função principal de estabelecer diretrizes estratégicas em temas como "habitação, mobilidade urbana, desenvolvimento econômico, meio ambiente e regulação da ocupação do solo." (CONFERÊNCIA METROPOLITANA DA RMVA, [s.d.]).

Apesar das descontinuidades administrativas, que culminaram, em diversos momentos, na interrupção das atividades vinculadas à elaboração do PDDI entre os anos de 2013 e 2018, bem como, das perdas de mobilização do setor popular na sua elaboração (CALDEIRA JUNIOR, 2018), o Projeto de Lei do PDDI foi aprovado pelo Conselho Deliberativo de Desenvolvimento Metropolitano (CDDM) da RMVA no mês de novembro de 2019 (SECRETARIA DE DESENVOLVIMENTO ECONÔMICO, 2019).

Ademais, o macrozoneamento deverá possibilitar orientar o desenvolvimento da RMVA sob os aspectos culturais, econômicos e ambientais, considerando as peculiaridades dos municípios que a integram e as demandas regionais para maior equilíbrio e efetividade das políticas públicas (CALDEIRA JUNIOR, 2018).

Projeto de Lei Complementar (PLC) 11/15 para instituição da Região Metropolitana de Montes Claros

O Norte de Minas, de acordo com estudos recentes desenvolvidos pelo IBGE (2017), é composto por 86 municípios, compreendendo uma área territorial de 124007,2 km2 e população total de 1.574 .501 habitantes. 0 município, que recebe a classificação de Capital Regional, sobressai em função do seu porte populacional, formada por uma população de 590.615 habitantes - dados do IBGE (2010), com a projeção para o ano de 2020 de 653.186 habitantes, sendo reconhecido como cidade de porte médio.

Montes Claros é um município de influência regional que exerce forte atração no noroeste mineiro, sobretudo, por motivos de compras, pela oferta de ensino superior, de serviços de saúde e como fornecedor de insumos para 
produtores agropecuários. Ressaltam-se nessa área de influência as longas distâncias de conexão de rede urbana pela ocupação esparsa da região (IBGE, 2008). Sobre a consolidação do polo regional, Gomes (2007, p.18-19) enfatiza que:

Montes Claros é uma cidade média, tanto em termos populacionais como funcionais, sendo o mais importante pólo da região do Norte de Minas, que é uma região que se destaca no âmbito estadual e nacional por apresentar baixos indicadores socioeconômicos. A posição central e hierarquicamente superior de Montes Claros na rede urbana do Norte de Minas se consolidou ao longo do seu processo de formação.

Ainda sobre seu processo de desenvolvimento, a cidade de Montes Claros, centro urbano regional de porte médio, é conformada, de acordo com estudos desenvolvidos por França (2012), pelo processo de aglomeração urbana descontínua, visto que estabelece uma rede de conexões com municípios que integram o Norte de Minas por configurar uma centralidade e pela oferta de bens e serviços, sem, contudo, conformar o processo de conurbação. Nesse sentido, destacam-se as relações de dependência e de trocas de municípios vizinhos com a capital regional, sobretudo do ponto de vista socioeconômico, pela concentração de serviços de educação, saúde, comércios diversificados e oportunidades de emprego (FRANÇA, 2012). Infere-se que tal situação intensifica o movimento pendular e, consequentemente, agrava os problemas de mobilidade intermunicipal.

Nesse processo, os vínculos estabelecidos são de ordem socioeconômica, com independência do ponto de vista político-administrativo, e não resultam na conformação de mancha urbana pela continuidade do tecido urbano e de eixos viários (SOUZA, 2011). Nessa situação, pode-se dizer que os municípios se integram pelo movimento pendular que caracteriza o dinamismo do centro urbano de porte médio em Montes Claros.

De acordo com a Constituição do Estado de Minas Gerais, o processo legal de reconhecimento das regiões metropolitanas pressupõe, dentre outros fatores, a avaliação da intensidade do processo de conurbação e dos movimentos pendulares entre o núcleo metropolitano e municípios vizinhos. Ressalta-se, entretanto, que no caso específico da Mesorregião do Norte de Minas, o fato de ocupar uma posição de isolamento quando comparada às demais mesorregiões que integram o Estado, associado às fragilidades econômicas e sociais (GOMES, 2007), caracterizam a urgência quanto ao direcionamento de investimentos e ao processo de gestão integrada para estímulo ao desenvolvimento urbano regional.

Não obstante, é importante mencionar que a consolidação da RMMOC constitui estratégia de desenvolvimento no que tange o direcionamento de políticas públicas, diante da possibilidade de obtenção de recursos orçamentários, que influenciam na dinâmica da rede urbana. As relações intermunicipais, que seriam estabelecidas por meio da proposta Região Metropolitana, associado a possibilidade de constituição de um Fundo de Metropolitano de Montes Claros, poderiam contribuir para a arrecadação de recursos provenientes das esferas federal e estadual para a realização de investimentos em setores de interesse comum entre os municípios, como exemplo, transporte, saúde, segurança e recursos hídricos (FRANÇA; COSTA, 2019). 
Sobre o Projeto de Lei Complementar (PLC) 11/15 para instituição da Região Metropolitana de Montes Claros (Figura 4), Brum e França (2017) colocam que a reabertura do Projeto de Lei (antigo PLC 4/11 e PLC51/02), visa constituir ações integradas para melhoria das condições de saúde, educação, transporte e segurança entre os municípios previstos para integração metropolitana. Para tanto, o projeto contempla além de Montes Claros, outros 10 municípios, bem como, a consolidação do Colar Metropolitano. Tal proposta foi anteriormente prevista pelo Projeto arquivado de Lei Complementar 51/2002 ${ }^{5}$ e, a partir da Lei Complementar 11/15, foram acrescidos outros 8 municípios integrantes da região metropolitana (BRUM, FRANÇA, 2017).

No que tange o andamento de tal Projeto de Lei Complementar, conforme o site da Assembléia Legislativa de Minas Gerais, no momento, o projeto se encontra na Comissão de Fiscalização Financeira e Orçamentária aguardando parecer da comissão.

Figura 4. Municípios que irão compor a Região Metropolitana de Montes Claros a partir do Projeto de Lei Complementar 11/15. Fonte: Portal Minas, 2017.

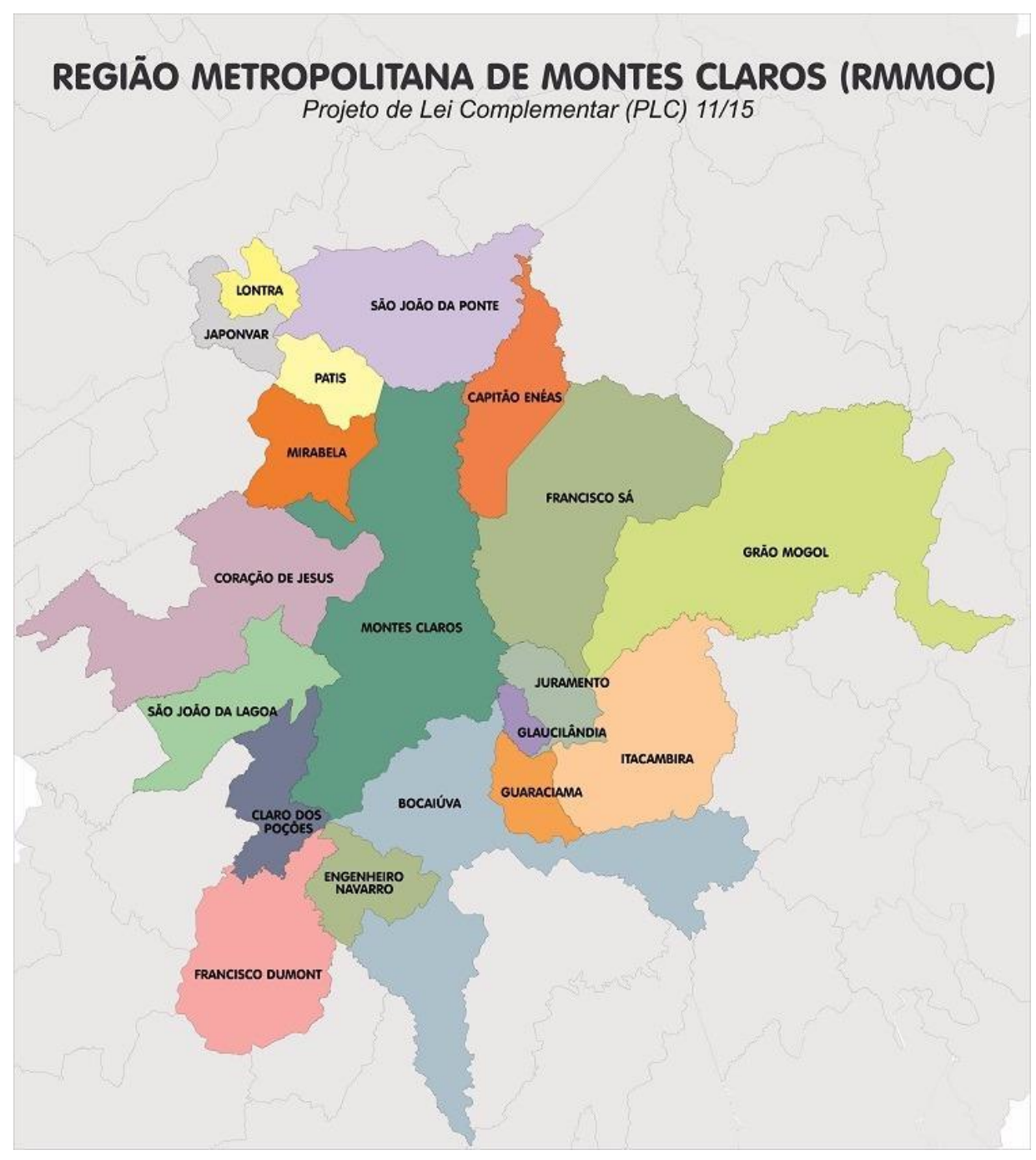

${ }^{5}$ O PLC 11/15 tem como origem o PLC 4/11, que por sua vez se origina do PLC 51/02. 


\section{CONSIDERAÇÕES FINAIS}

Apesar das regiões metropolitanas consolidadas apresentarem características diferentes em relação ao processo de estruturação urbana, já que a Região Metropolitana de Belo Horizonte é de ocupação mais antiga quando comparado a Região Metropolitana do Vale do Aço, verifica-se que o processo de regionalização em ambas foi impulsionado pelos investimentos em transporte e pela consolidação de núcleos populacionais próximos à equipamentos públicos e indústrias de maior porte. No caso de $\mathrm{BH}$, os investimentos na infraestrutura viária que conectam a área central do município com as áreas periféricas, associadas à implantação da Cidade Industrial Coronel Juventino Dias, do Aeroporto da Pampulha e do Aeroporto Tancredo Neves, dentre outros investimentos públicos realizados, sobretudo na década de 1940, consolidaram os principais eixos de expansão e o processo de conurbação com os municípios vizinhos. Já no caso da RMVA, o processo de ocupação e desenvolvimento econômico da região do Vale do Aço foi motivado pela implantação da linha ferroviária e pela instalação de grandes siderúrgicas, o que definiu o processo de polarização e conurbação dos três principais municípios que conformam a região metropolitana: Coronel Fabriciano, Ipatinga e Timóteo.

Em termos populacionais, constata-se que, tendo em vista as exigências estabelecidas pela Lei Complementar $n^{\circ} 88$ de 2006 de Minas Gerais quanto ao porte mínimo de 600 mil habitantes para a configuração de região metropolitana, verifica-se que, atualmente, a Região Metropolitana do Vale do Aço não atenderia esse requisito, contudo, a própria legislação resguarda as regiões metropolitanas que foram instituídas antes de sua promulgação, como é o caso da RMVA. Não obstante, a importância do processo de regionalização da área está associada à necessidade de direcionamento de investimentos em funções públicas de interesse comum dos municípios que a constituem.

Ao se estabelecer uma sucinta análise comparativa do processo de regionalização em Minas Gerais, verifica-se que, embora as regiões apresentem divergências quanto às escalas territoriais: Belo Horizonte configura um grande centro urbano enquanto o aglomerado formado por Ipatinga - Coronel Fabriciano Timóteo e o Município de Montes Claros, no Norte de Minas, configuram centros médios, ambos comungam problemas de gestão no que tange aspectos socioeconômicos. No caso específico das duas regiões metropolitanas mineiras, considerando a heterogeneidade dos municípios que conformam as mesmas, ressalta-se a dificuldade de conciliar interesses locais na gestão metropolitana e, consequentemente, a distribuição desigual dos recursos orçamentários provenientes do fundo metropolitano, destinados para investimentos em melhorias de infraestrutura urbana, na implementação de equipamentos públicos de demanda regional e no processo de descentralização urbana, no intuito de se evitar a sobrecarga de infraestrutura dos núcleos e para melhorias de mobilidade. Além disso, são significativos os impactos em áreas de vulnerabilidade ambiental e de segregação sócio espacial. 
Não obstante, considerando o interesse do Projeto de Lei Complementar (PLC) 11/15 de instituição da Região Metropolitana de Montes Claros, à luz dos critérios estabelecidos pelo Estatuto da Metrópole e do IBGE, o município de Montes Claros não apresenta o processo de conurbação com os demais municípios que integrariam a referida Região Metropolitana. Ressalta-se, todavia, a forte dependência dos municípios do Norte de Minas em relação à Montes Claros em função da ocupação espraiada, constituída por redes de longa distância, que prejudicam a articulação com outros centros regionais. Ainda, a grande desigualdade socioeconômica que assola o Norte de Minas, configurando áreas de extrema pobreza, geram a necessidade emergente de direcionamento de políticas públicas integradas que poderiam ser alcançadas com a instituição da Região Metropolitana.

Importante mencionar que, se baseado no censo do IBGE (2010), a RMMOC também não atenderia os critérios legais da mencionada Lei Complementar n88 de 2006 de Minas Gerais, que determina uma população mínima de 600 mil habitantes para a instituição de regiões metropolitanas no estado. Conforme os dados de 2010 a região conta com $590.615^{6}$ habitantes. Contudo, a projeção para o ano de 2020 é uma população de $653 \cdot 186^{7}$. Assim sendo, confirmada a estimativa este requisito legal será atendido.

Por fim, vale ressaltar que, considerando a diversidade populacional, de condições de ocupação e de necessidades socioeconômicas que caracterizam as regiões metropolitanas instituídas, os critérios rígidos que legalmente caracterizam as regiões metropolitanas, muitas vezes são limitadores quanto ao direcionamento de políticas públicas integradas adequadas às especificidades locais.

\section{REFERÊNCIAS}

AGÊNCIA DE DESENVOLVIMENTO DA REGIÃO METROPOLITANA DE BELO HORIZONTE (RMBH). Pensar metropolitano [livro eletrônico]. O problema é a chuva? Agência de desenvolvimento da Região Metropolitana de Belo Horizonte, 1 ed. Belo Horizonte: Gabrielle Sperandio Malta, 2020.

AGÊNCIA DE DESENVOLVIMENTO DA REGIÃO METROPOLITANA DE BELO HORIZONTE (RMBH). Pensar metropolitano [recurso eletrônico]: 10 anos de implantação da agência RMBH. Belo Horizonte: Fundação João Pinheiro, Agência de Desenvolvimento da $\mathrm{RMBH}, 2019.180 \mathrm{p}$.

BALBIM, Renato Nunes; BECKER, Maria Fernanda; COSTA, Marco Aurelio. Desafios contemporâneos na gestão das regiões metropolitanas. Revista Paranaense de Desenvolvimento, Curitiba, n.120, p.149-176, jan./jun. 2011, p. 149-176.

BARBOSA, Kênia de Souza. Por que a gestão da Região Metropolitana do Vale do Aço não sai do papel? Belo Horizonte, $2010.134 \mathrm{f}$. Dissertação (Mestrado em Arquitetura e Urbanismo) - Núcleo de Pós- Graduação em Arquitetura e Urbanismo da Escola de Arquitetura da Universidade Federal de Minas Gerais, Belo Horizonte, 2010.

BRASIL. Constituição (1988). Constituição da República Federativa do Brasil, 1988. Federal. Brasília: Senado Federal, Centro Gráfico, 1988, $292 \mathrm{p}$.

\footnotetext{
${ }^{6}$ Os cálculos foram feitos considerando os dados de cidades do IBGE. Ademais o termo cidade compreende o perímetro urbano da sede do município.

${ }^{7}$ Idem.
} 
BRASIL. Lei ${ }^{\circ} 13.089$ de 12 de janeiro de 2015. Institui o Estatuto da Metrópole, altera a Lei n 10.257, de 10 de junho de 2001, e dá outras providências. Brasília, Congresso Nacional, 2015. Disponível em: <http://www.planalto.gov.br/ccivil_03/_ato20152018/2015/lei//13089.htm>. Acesso em: 19 mar. 2021.

BRASIL. Lei Complementar no 14 de 08 de junho de 1973. Estabelece as regiões metropolitanas de São Paulo, Belo Horizonte, Porto Alegre, Recife, Salvador, Curitiba, Belém e Fortaleza. Brasília, Congresso Nacional, 1973. Disponível em: <http://www.planalto.gov.br/ccivil_03/leis/lcp/lcp14.htm>. Acesso em: 19 mar. 2021.

BRUM, Brunna Marques Sepulveda; FRANÇA, lara Soares de. Região Metropolitana de Montes Claros (RMMOC): viabilidade, desafios e sua materialização. In: FÓRUM ENSINO, PESQUISA, EXTENSÃO, GESTÃo (FEPEG), 11. 2017. Montes Claros, MG. Anais.Montes Claros: Unimontes, 2017

CALDEIRA JUNIOR, Roberto Alves. Avaliação do processo de elaboração do Plano Diretor de Desenvolvimento Integrado da Região Metropolitana do Vale do Aço - MG. Dissertação (Magister Scientiae) - Programa de Pós-Graduação em Arquitetura e Urbanismo da Universidade Federal de Viçosa, Viçosa, 2018.

CONFERÊNCIA METROPOLITANA DA RMVA. O PDDI. Disponível em: <https://conferenciarmva.wordpress.com/home/pddi/o-pddi/>. Acesso em: 19 mar. 2021.

CÔRREA, Roberto Lobato. Reflexões sobre a dinâmica recente da rede urbana brasileira. In: ENCONTRO NACIONAL DA ANPUR, IX, 2001, Rio de Janeiro. Anais... Rio de Janeiro: Associação Nacional de Pós-Graduação e Pesquisa em Planejamento Urbano e Regional, 2001, p.424-430.

COSTA, Geraldo Magela; SANTOS, Deusdedit Soares dos. Mudanças Populacionais, Espaciais e do Emprego em Aglomerações Urbanas Economicamente Dinâmicas: o caso da Região Metropolitana do Vale do Aço. Anais do XIII Encontro da Associação Brasileira de Estudos Populacionais, realizado em Ouro Preto, Minas Gerais, Brasil de 4 a 8 de novembro de 2002. p. 1-18.

FRANÇA, lara Soares de; COSTA, Valéria Aparecida Moreira. Metropolização, interações espaciais e a proposta de criação da Região Metropolitana de Montes Claros/MG. OKARA: Geografia em debate, João Pessoa, v. 13, n. 2, p. 538-560, 2019.

FRANÇA, lara Soares de; SOARES, Beatriz Ribeiro. Rede urbana regional, cidades médias e centralidades. Revista Brasileira de Estudos Urbanos e Regionais, São Paulo, v.14, n.2, p. 169-185, nov. 2012.

FRANÇA, lara Soares de. Aglomeração Urbana Descontínua de Montes Claros/MG: novas configurações socioespaciais. 2012. $399 f$. Tese (Doutorado em Geografia) - Programa de PósGraduação em Geografia da Universidade Federal de Uberlândia, Uberlândia, 2012. Disponível em: <https://repositorio.ufu.br/handle/123456789/15946>. Acesso em: 19 mar. 2021.

FÓRUM NACIONAL DE ENTIDADES METROPOLITANAS. Região Metropolitana de Belo Horizonte (MG). 2018a. Disponível em: <http://fnembrasil.org/mg/>. Acesso em: 19 mar. 2021.

FÓRUM NACIONAL DE ENTIDADES METROPOLITANAS. Região Metropolitana do Vale do Aço (MG). 2018b. Disponível em: <http://fnembrasil.org/mg/>. Acesso em: 19 mar. 2021.

GOMES, Fernanda Silva. Discursos contemporâneos sobre Montes Claros: (Re) estruturação urbana e novas articulações urbanoregionais. Belo Horizonte. 2007. 182 f. Dissertação (Mestrado em Arquitetura e Urbanismo). Núcleo de Pós-graduação em Arquitetura e Urbanismo da Escola de Arquitetura. Universidade Federal de Minas Gerais, Belo Horizonte, 2007. Disponível em: <http://www.bibliotecadigital.ufmg.br/dspace/handle/1843/RAAO-7BMQ8A>. Acesso em: 19 mar. 2021.

INSTITUTO BRASILEIRO DE GEOGRAFIA E ESTATÍSTICA (IBGE). Brasil tem três novas regiões metropolitanas. 2017. Disponível em: <https://agenciadenoticias.ibge.gov.br/agencia-noticias/2012-agencia-de-noticias/noticias/9868-brasil-tem-tres-novas-regioesmetropolitanas>. Acesso em: 19 mar. 2021.

INSTITUTO BRASILEIRO DE GEOGRAFIA E ESTATÍSTICA (IBGE). Cidades. 2010. Disponível em: <https://cidades.ibge.gov.br/>. Acesso em: 19 mar. 2021.

INSTITUTO BRASILEIRO DE GEOGRAFIA E ESTATÍSTICA [IBGE]. Divisão regional do Brasil em regiões geográficas imediatas e regiões geográficas intermediárias. Rio de Janeiro: IBGE, 2017. 82p.

INSTITUTO BRASILEIRO DE GEOGRAFIA E ESTATÍSTICA (IBGE). IBGE atualiza a lista de municípios que integram os recortes territoriais brasileiros. Rio de Janeiro: IBGE, 2020, online. Disponível em: < https://agenciadenoticias.ibge.gov.br/agencia-sala-deimprensa/2013-agencia-de-noticias/releases/29465-ibge-atualiza-a-lista-dos-municipios-que-integram-os-recortes-territoriaisbrasileiros2>. Acesso em: 17 mar. 2021.

INSTITUTO BRASILEIRO DE GEOGRAFIA E ESTATÍSTICA (IBGE). Regiões de influência das cidades - 2007. Rio de Janeiro: IBGE, 2008. 201p. Disponível em: <http://www.mma.gov.br/estruturas/PZEE/_arquivos/regic_28.pdf>. Acesso em: 17 mar. 2021. 
LACERDA, Norma. Fragmentação e integração: movimentos de (re)estruturação espacial das metrópoles brasileiras. In: RIBEIRO, A.C., LIMONAD, E., GUSMÃO, P.P. (Org.) Desafios ao planejamento. Rio de Janeiro: ANPUR; Letra Capital, 2012. p. 21-42.

MARRA, Natália Cardoso. Cooperação Interinstitucional como Instrumento de Gestão da Região Metropolitana de Belo Horizonte e de Promoção do Desenvolvimento Local. 2012. 155 f. Dissertação (Mestrado em Gestão Social, Educação e Desenvolvimento Local) Centro Universitário UNA, Belo Horizonte, 2012.

MENCIO, M. A constitucionalidade dos critérios de criação das Regiões Metropolitanas, Aglomerações Urbanas e Microrregiões previstos na Lei Federal brasileira. Revista Digital de Derecho Administrativo, n. 13, p. 161-192, jun. 2015. Disponível em: <https://doi.org/10.18601/21452946.n13.09>. Acesso em: 19 mar. 2021.

MENDONÇA, Jupira Gomes de; ANDRADE, Luciana Teixeira de; DINIZ, Alexandre Magno Alves. Introdução: Mudanças e permanências na estrutura socioeconômica e territorial na Região Metropolitana de Belo Horizonte. In: ANDRADE, Luciana Teixeira de; MENDONÇA, Jupira Gomes de; DINIZ, Alexandre. Belo Horizonte [recurso eletrônico]: transformações na ordem urbana. 1ed. Rio de Janeiro: Letra Capital [Observatório das Metrópoles], 2015, p. 15-32.

MINAS GERAIS, Governo de. Plano Diretor de Desenvolvimento Integrado da Região Metropolitana de Belo Horizonte [RMBH]. Definição das Propostas de Políticas Setoriais, Projetos e Investimentos Prioritários, 2011. Vol. 1. Belo Horizonte: Agência RMBH, 2011. Disponível em: <http://www.agenciarmbh.mg.gov.br/plano-diretor-de-desenvolvimento-integrado-da-regiao-metropolitanade-belo-horizonte/>. Acesso em: 03 de nov. 2016.

MINAS GERAIS. Constituição (1989). Constituição do estado de Minas Gerais, 1989. 20. ed. Belo Horizonte: Assembleia Legislativa do Estado de Minas Gerais, 1989. Disponível em:

<https://www.almg.gov.br/export/sites/default/consulte/legislacao/Downloads/pdfs/ConstituicaoEstadual.pdf>. Acesso em: 19 mar. 2021.

MINAS GERAIS. Lei complementar no 51, de 30 de dezembro de 1998. Institui a Região Metropolitana do Vale do Aço, dispõe sobre sua organização e funções e dá outras providências. Assembleia Legislativa do Estado de Minas Gerais, 1998. Disponível em:

<https://www.almg.gov.br/consulte/legislacao/completa/completa.html?num=51\&ano=1998\&tipo=LCP>. Acesso em: 19 mar. 2021.

MINAS GERAIS. Lei complementar $n^{\circ} 88$ de 12 de janeiro de 2006. Dispõe sobre a instituição e a gestão de região metropolitana e sobre o fundo de desenvolvimento metropolitano. Belo Horizonte, Palácio da Liberdade. Disponível em:

<https://www.almg.gov.br/consulte/legislacao/completa/completa.html?tipo=LCP\&num=88\&ano=2006>. Acesso em: 19 mar. 2021.

MINAS GERAIS. Lei complementar no 90, de 12 de janeiro de 2006. Dispõe sobre a Região Metropolitana do Vale do Aço. Assembleia Legislativa do Estado de Minas Gerais, 2006. Disponível em:

<https://www.almg.gov.br/consulte/legislacao/completa/completa.html?tipo=LCP\&num=90\&comp=\&ano=2006>. Acesso em: 19 mar. 2021.

MINAS GERAIS. Projeto de Lei complementar no 11, de 31 de março de 2015. Institui a Região Metropolitana de Montes Claros, dispõe sobre sua organização e funções e dá outras providências. Assembleia Legislativa do Estado de Minas Gerais, 2015. Disponível em: <https://www.almg.gov.br/atividade_parlamentar/tramitacao_projetos/interna.html?a=2015\&n=11\&t=PLC>. Acesso em: 19 mar. 2021.

MOURA, Rosa. A dimensão urbano-regional na metropolização contemporânea. Revista Eure, v. 38, n.15, setembro 2012. p. 5-31.

OBSERVATÓRIO DAS METRÓPOLES [Instituto Nacional de Ciência e Tecnologia]. Regiões Metropolitanas do Brasil. Rio de Janeiro: Observatório das Metrópoles, 2010.

OLIVEIRA, Bianca Simoneli de. Rede urbana brasileira: algumas reflexões teóricas. Revista Formação, São Paulo, v.2, n.15, p.100-109, 2008.

PEREIRA, José Abílio (coord.). Regiões Metropolitanas em Minas Gerais. Belo Horizonte: Crea-MG, 2007. 40p. Disponível em: <http://www.crea-mg.org.br/im ages/Documento s/Regies-Metropolitanas.pdf>. Acesso em: 29 ago. 2018.

SANTOS, Marcela de Oliveira Santos. Interpretando o estatuto da metrópole: comentários sobre a lei n¹3.089/2015. In: Marguti, Bárbara Oliveira (org); Costa, Marco Aurélio (org.); Favarão, César Buno (org.). Brasil metropolitano em foco: desafios à implementação do Estatuto da Metrópole. Brasília: Ipea, 2018. 511 p. (Série Rede Ipea. Projeto Governança Metropolitana no Brasil; v. 4).

SECRETARIA DE DESENVOLVIMENTO ECONÔMICO. Conselho Deliberativo de Desenvolvimento Metropolitano aprova Projeto de Lei do PDDI. Disponível em: <http://www.desenvolvimento.mg.gov.br/application/noticias/noticia/991/conselho-deliberativo-dedesenvolvimento-metropolitano-aprova-projeto-de-lei-do-pddi>. Acesso em: 17 mar. 2021. 
SEGUNDO, Gemilson Soares da Silva; FONTES, Renato Barbosa; MENDONÇA, Jupira Gomes de; ANDRADE, Luciana Teixeira de. As metrópoles e a Covid-19: Dossiè Nacional - Análise da Região Metropolitana de Belo Horizonte (RMBH). Belo Horizonte: Observatório das Metrópoles, 2020.

SOUZA, Joseane de. A expansão urbana de Belo Horizonte e da Região Metropolitana de Belo Horizonte: o caso específico do município de Ribeirão das Neves. Belo Horizonte, 2008. 194f. Dissertação (Doutorado em Demografia) - Centro de Desenvolvimento e Planejamento Regional da Faculdade de Ciências Econômicas, Universidade Federal de Minas Gerais, Belo Horizonte, 2008.

SOUZA, Marcelo Lopes de. Abc do Desenvolvimento Urbano. 6.ed..Rio de Janeiro: Bertrand Brasil, 2011.192p.

TONUCCI FILHO, João Bosco Moura. Dois momentos do planejamento metropolitano em Belo Horizonte: um estudo das experiências do PLAMBEL e do PDDI-RMBH. 2012. 236f. Dissertação (Mestrado em Arquitetura e Urbanismo) - Faculdade de Arquitetura e Urbanismo da Universidade de São Paulo, São Paulo, 2012. Disponível em:

<http://www.teses.usp.br/teses/disponiveis/16/16139/tde-23052012-

151814/publico/dissertacao_planejamento_RMBH_jtonucci.pdf>. Acesso em: 19 mar. 2021.

UFMG. Apresentação do 10 Seminário Metropolitano Macrozoneamento RMBH. Belo Horizonte, 2014. Disponível em: <http://www.rmbh.org.br/pt-br/repositorio/municipios/apresenta-es-do-1-semin-rio-metropolitano-do-macrozoneamentoapresenta-o-manh>. Acesso em: 15 de dez. 2016. 